\title{
Determination of phthalates in particulate matter and gaseous phase emitted into the air of the working environment
}

\author{
M. Szewczyńska ${ }^{1}$ (D) M. Pośniak ${ }^{1}$ (D) E. Dobrzyńska ${ }^{1}$ (D)
}

Received: 7 March 2019 / Revised: 29 May 2019 / Accepted: 10 June 2019 / Published online: 17 June 2019

(c) The Author(s) 2019

\begin{abstract}
The paper presents the results of phthalates measurements in 4 companies producing or processing materials made of rubber and plastics. Six priority phthalates were determined in air samples both in the respirable and inhalable particle fractions. For the determination of phthalates, GC/MS was applied, which ensures the determination of the method at the level of $0.066 \mu \mathrm{g} /$ $\mathrm{m}^{3}$ for fibreglass filter and polyurethane foam and $0.022 \mu \mathrm{g} / \mathrm{m}^{3}$ for Amberlite resin XAD-2, while taking $720 \mathrm{~L}$ of air samples. The results of the measurements showed that dimethyl phthalate, diethyl phthalate and dibutyl phthalate (DBP) dominated in all the investigated companies in the gaseous phase of air sampling. For example, in a company producing rubber details for car accessories, the concentration of DBP ranged from 54 to $74 \%$ of the total phthalate concentration determined in the gaseous phase. The inhalable particle fraction was dominated by two compounds, i.e. DBP and di(2-ethylhexyl) phthalate DEHP, and their total concentration was a significant percentage, on average over $83 \%$ of the sum of all phthalates determined in the inhalable fraction in the investigated companies. As particle size affects the location of phthalate deposition in the respiratory tract, the determination of concentration levels of individual phthalates in the gaseous phase and in inhalable and respirable fractions can provide valuable information that can be used to improve the health and safety of workers at work.
\end{abstract}

Keywords Phthalate esters $\cdot$ Inhalable fraction $\cdot$ Respirable fraction $\cdot$ Particle size distribution

\section{Introduction}

Endocrine-disrupting chemicals (EDCs) can have a harmful effect on the endocrine system. They interfere with natural hormones that act in very small quantities and at a specific time in order to regulate the development, growth, reproduction, metabolism, immunity and behaviour of the body. EDCs can lead to, among other, fertility disorders, disorders of the genital organs, hormone-dependent cancer (such as breast cancer, prostate cancer, ovarian cancer and testicles), foetal damage, including the development of the foetus's nervous system, and even disorders of metabolism, obesity and diabetes mellitus. Currently, there are more than 560 compounds known to be able to disrupt the function of the

Editorial responsibility: M. Abbaspour.

M. Szewczyńska

mapol@ciop.pl

1 Department of Chemical, Aerosol and Biological Hazards, Central Institute for Labour Protection -National Research Institute, Czerniakowska 16, 00-701 Warsaw, Poland endocrine system. There may be many more of this type of substance, considering that the CAS (Chemical Abstract Service) database currently contains more than 133 million unique organic and inorganic chemicals, such as alloys, coordination compounds, minerals, mixtures, polymers and salts. Over the last decade, numerous studies have confirmed the occurrence of exposure and adverse effects of various chemicals that are commonly found in water, air and food at low concentrations levels (Han et al. 2018; Chen et al. 2018; Ten Dam et al. 2012) and interact with the endocrine system of humans and animals (Colborn et al. 1993; Safe 2000; Cooper and Kavlock 1997). In addition to the external environment, it appears that the internal environment can also be a major source of contamination by endocrine active or suspected endocrine agents (Wallace et al. 1985; Moreau-Guigon and Chevreuil 2014). Many known or suspected EDCs can be found in indoor air due to their use in finishing materials. The growing accumulation of contaminants in closed rooms can be explained by their equipment and the presence of new building materials. Endocrine disruptors, apart from substances of natural origin, include many chemicals from industry, agriculture, technological 
processes and pharmacy. They contain phthalates (used in the manufacture of plastics), alkylphenols (present in detergents, surfactants and used as antioxidants and additives to lubricating oils), polychlorinated PCBs (formerly used in electrical equipment), dioxins (released from incineration sites), organochlorinated pesticides and organohalogens (used as flame retardants) (Dodson et al. 2012).

These types of substances can cause a substantial proportion of occupational diseases, which have a negative impact on workers' quality of life and ability to work. It is estimated that EU spends hundred billion EURs a year on treating EDC-related diseases and maintaining people who are unable to work because of health problems.

Phthalate esters (PAEs), considered endocrine active, are synthetic chemical esters of phthalic acid known as "plasticizers" (Sathyanarayana 2008). They are a group of organic compounds that are commonly used as additives to plastics changing their physical properties such as shreddability or plasticity. Phthalates are broadly used in the manufacture of plastics, insect repellents, synthetic fibres, lubricants, and in the construction industry, automotive, packaging and medicinal materials, cosmetics and personal care products (Quintana et al. 2007; Bergh et al. 2010; Liang et al. 2008). They are used for phthalate-glycerine resins, as a base for phthalic paints and varnishes, adhesives (synthetic gum arabic) and certain laminates, air fresheners, cleaning agents and detergents. Although some studies have shown that phthalates can cause hormonal interference and affect human health, they are used in polymeric materials such as cellulose esters and copolymers of vinyl chloride (PVC) (Quintana et al. 2007; Bergh et al. 2010; Tsuyoshi et al. 2003). PVC plasticized with di(2-ethylhexyl)phthalate (DEHP) is used, inter alia, in blood collection and maintenance containers, for continuous dialysis, kits for transfusion and infusion. The potential for toxicity of phthalate esters results from their rapid transformation in the body into even more toxic metabolites. With regard to the risks to the human health, there are many studies demonstrating harmful effects, such as anti-androgenic reactions reducing concentrations of androgens. The results of the study collected by Jurewicz and Hanke (2011) suggest strong indications that phthalates increase the risk of allergy and asthma and have an adverse effect on neurological development in children. Exposure to phthalates adversely affects the level of reproductive hormones (luteinizing hormone, free testosterone, sex hormone-binding globulin) or thyroid function. Exposure to endocrine disruptors in the mother's womb can have lifelong effects and even consequences for the next generation. In addition, some studies have also shown negative associations between exposure to phthalates and impaired semen quality (concentration, morphology, motility). Given the suggested health effects, further epidemiological studies are urgently needed, as well as the implementation of a prevention policy. So far, some phthalates (e.g. butyl benzyl phthalate (BBP), dibutyl phthalate (DBP) or di(2-ethylhexyl)phthalate (DEHP)) have been included in the REACH Regulation on the Registration, Evaluation, Authorisation and Restriction of Chemicals (EC) 1907/2006 as substances with similar regulatory requirements as those of very high concern. The United States Environmental Protection Agency (EPA) has classified BBP and DEHP as substances with potential carcinogenic effects for humans (U.S. EPA 2007). DEHP is listed as a category 1B carcinogen under the globally harmonized system of classification and labelling of chemicals (GHS) and therefore banned in toys, childcare articles, cosmetics and medical devices (Bui et al. 2016).

It should be stressed that phthalates are not chemically bound to the products in which they occur. They are released into the environment where they can be delivered to the human body through ingestion, inhalation and absorption through the skin (Meeker et al. 2009; Zota et al. 2014). Working with plastics in which these compounds may have been used increases the risk of exposure. Most of the studies published so far concerned biomonitoring and used urine or plasma as a measurement for exposure to phthalates (Philips et al. 2017; Zota et al. 2014; Kolena et al. 2014; Johns et al. 2015). Meanwhile, PAE exposure in the air is more common (Song et al. 2015; Chi et al. 2017). Review made by Kashyap and Agarwal (2018) phthalate levels was found to be higher in indoor air as compared to outdoor air. The authors explain this by the presence of the main sources of phthalates indoors, while faster degradation occurs in the outdoor environment. Hence, the literature contains numerous studies on phthalates indoor air pollution (Rudel et al. 2003; Abdallah et al. 2008; Pei et al. 2013), although only a few concern the working environment, such as offices (Song et al. 2015). Some studies reported on exposure to phthalates, which are used as plasticizers in the rubbermanufacturing industry (IARC 2012). Places in companies and factories where different types of plastics are processed, including many packaging materials and plastic parts, can be expected to pose a potential threat to the people working there. PAEs concentrations can be expected to be quite high at such locations. For example, in Korea, Kim (2016) carried out a risk assessment of workers producing or operating DEHP in workplaces where this phthalate was used as plasticizer, insecticide and printing ink solvent. The results of this study indicate an average DEHP exposure of $0.158 \pm 0.306 \mathrm{mg} / \mathrm{m}^{3}$ at workplaces in manufacturing industry, while at workplaces of handling DEHP at an average exposure of $0.210 \pm 0.257 \mathrm{mg} / \mathrm{m}^{3}$. Phthalates can be present in the workplace air as either aerosols or vapours depending on source materials, vapour pressure and processing temperatures (Hines et al. 2010). As mentioned above, phthalates are a common environmental pollutant, and man is exposed to their effects at almost every stage of the way from the air, 
water, food. In order to limit exposure to internally released active substances, it is necessary to provide as much data as possible on the concentration levels of endocrine disruptors by monitoring these substances in different environments. In this article, we wanted to draw attention to one of the basic but poorly identified environments, which is the working environment in which exposure to basic phthalates occurs. Since there was little research on phthalate pollution in this environment, it was interesting to determine which phthalates and in what form, whether gas or particulate matter, are emitted into the air in the working environment. Therefore, 4 companies producing or processing rubber and plastic materials were selected in this article and air samples were taken in order to estimate PAE concentration levels in both the gaseous and particulate phases. For the working environment, it has been assumed that the health effects of inhalation of particles are related on their diameter size as well as physicochemical and biological properties. This in turn affects the respiratory system of the particles and its interaction with the cells and tanks at the deposition site. Depending on the size of the particles, they are deposited in the different regions, namely, nasopharyngeal, tracheobronchial region and alveolar region. In order to assess occupational exposure to particles, they are determined in the following areas: inhalable, thoracic and respirable, respectively.

Since the size and location of particles in the respiratory tract of workers are important in the working environment, and the inhalable fraction was additionally collected with a finer respirable fraction. For sampling purposes, aerodynamic diameter conventions have been agreed, which define what should be collected according to which region is of interest for the substance and hazard (WHO 1999). The inhalable fraction is the part of the dust cloud that can be inhaled into the nose or mouth (for particles with an aerodynamic diameter of less than $100 \mu \mathrm{m}$ ). The respirable fraction is that part of the inhaled airborne particles that can pass beyond the end bronchi into the gas exchange area of the lungs (for particles with an aerodynamic diameter of less than $4 \mu \mathrm{m}$ ). As exposure assessment is a fundamental and often weak element of the large epidemiological studies due to technical, logistical and financial constraints, the studies carried out will also provide original data on human exposure to a type of potentially endocrine-disrupting plastic additives. The determination of concentration levels of individual phthalates in the gaseous phase and in inhalable and respirable fractions will provide valuable information that can be used to improve the health and safety of workers at work.

\section{Materials and methods}

\section{Chemicals and materials}

All chemicals and solvents used for extraction and gas chromatography (GC) analysis were of HPLC grade. Phthalate Standard mixtures EPA Method 8061A Phthalate Esters Mixture including dimethyl phthalate (DMP), diethyl phthalate (DEP), dibutyl phthalate (DBP), butylbenzyl phthalate (BBP), di(2-ethylhexyl) phthalate (DEHP) and di- $n$-octyl phthalate (DnOP) were purchased from LCG Standards as stock solutions in hexane/acetone (80:20). The concentration of each phthalate was $1.0 \mu \mathrm{g} / \mathrm{mL}$.

\section{Sampling sites and conditions}

A question was sent to about 10 companies in Poland involved in the production and processing of plastics, asking if they would like to take part in the research on the determination of phthalates in the air of the working environment. We obtained permission to carry out the research from four out of ten companies. Therefore, air samples were collected in 4 companies producing or processing rubber, plastic and plastic materials. Characteristics of the selected companies are presented in Table 1. Samples were taken at workstations during the production of plastic advertising products; gluing of plastic elements; processing of plastic elements; milling cutting of plastic elements; vulcanizing presses; and extruders of plastic moulds. The measurement points were located at the workplace - the place where the employee was staying, with samples placed at the level of the employee's respiratory tract. According to the principles of workplace measurement and assessment of workers' exposure to chemicals, measurements are carried out over a period of $\min .75 \%$ of working time in shifts. Our measurements were based on the working environment, and the sampling time was $8 \mathrm{~h}$. In each company, at each workstation 3 samples were taken at the same time $(8 \mathrm{~h})$ - one sample at each shift. Since phthalates may be present in the environment both in particulate fraction and in the gaseous phase, a combined probe with IOM sampler (SKC, Inc., USA) and adsorption tube was used for air sampling. IOM sampler, developed at the Institute of Occupational Medicine (IOM) in Scotland, meets the ACGIH sampling criteria for inhalable and respirable molecular weight in the workplace. The front of the IOM probe cassette was equipped with MultiDust Foam Disc (polyurethane foam) and 25-mm-thick glass fibre filter (Whatman) was located in the back of the cassette. Passing through the air sampler at a flow rate of $2 \mathrm{~L} / \mathrm{min}$ as recommended for the IOM sampler, the fine particles pass through the polyurethane foam and stop at the filter (they are respirable fractions), while the larger diameter particles are 
Table 1 Operating characteristics of the surveyed companies

\begin{tabular}{|c|c|c|c|}
\hline & $\begin{array}{l}\text { Symbol of } \\
\text { the company }\end{array}$ & $\begin{array}{l}\text { Number of the } \\
\text { workplaces } \\
\text { tested }\end{array}$ & Characteristics of the company \\
\hline 1. & A & 8 & $\begin{array}{l}\text { Manufacture of plastic advertising products. Company A was engaged in the production of various types of } \\
\text { advertisement materials made of plastics and plexiglass. In one space }\left(300 \mathrm{~m}^{2}\right) \text {, many different tasks were } \\
\text { carried out, such as gluing, cutting, segregation and grinding of plastic parts, which may be important } \\
\text { when it comes to the number of phthalates determined. The company operated in a three-shift system. The } \\
\text { company did not have mechanical ventilation and air conditioning. Workers did not wear personal protec- } \\
\text { tive equipment }\end{array}$ \\
\hline 2. & $\mathrm{~S}$ & 3 & $\begin{array}{l}\text { The company produced plastic packaging. Measurements were taken at workstations at extruders, contain- } \\
\text { ers and tanks for handling plastics. The company operated in a three-shift system. The hall in which the } \\
\text { measurements were made was about } 800 \mathrm{~m}^{2} \text { in size. The company had mechanical ventilation and central } \\
\text { air conditioning. Employees used personal protective equipment: gloves and safety glasses }\end{array}$ \\
\hline 3. & $\mathrm{~V}$ & 12 & $\begin{array}{l}\text { The activity of the company is based on the production of rubber details for car accessories. In this com- } \\
\text { pany, measurements were taken on twelve vulcanizing presses, where plastic rubber compounds were } \\
\text { changed into highly elastic products. The company operated in a three-shift system. The hall where the } \\
\text { measurements were taken was about } 600 \mathrm{~m}^{2} \text {. The company had mechanical ventilation. Workers used } \\
\text { personal protective equipment: gloves and goggles }\end{array}$ \\
\hline 4. & $\mathrm{D}$ & 7 & $\begin{array}{l}\text { The company produced PVC, PP and drainage pipes. The measurements were taken at seven workplaces } \\
\text { on the pipe production line, including stations where composite mixers, extruders and injection mould- } \\
\text { ing machines were used. The company operated in a three-shift system. The hall where the measurements } \\
\text { were taken was about } 120 \mathrm{~m}^{2} \text {. The company had mechanical ventilation. Workers used personal protective } \\
\text { equipment: gloves }\end{array}$ \\
\hline
\end{tabular}

retained on the polyurethane foam. The inhalable fractions are the particles retained on the polyurethane foam and filter. The absorption tube filled with Amberlite XAD-2 resin (Sigma-Aldrich, USA) has been connected to IOM sampler in order to ensure the collection of PAEs present in both gaseous and particle fractions. IOM effectively captures particles with an aerodynamic diameter of up to $100 \mu \mathrm{m}$ and closely simulates how particles are inhaled from the workplace air. All samplers operated at a flow rate of $2 \mathrm{~L} /$ min for $8 \mathrm{~h}$ per sample.

\section{Sample pretreatment and analysis}

Samples were extracted from XAD-2 resin, glass fibre filter and polyurethane foam (PUF) using an ultrasonic cleaner for $30 \mathrm{~min}$, respectively, with a mixture of $3 \mathrm{~mL}$ dichloromethane/acetone (1:1) as an extraction solvent. The sample was analyzed by a gas chromatograph (7890A Agilent Technology Inc, USA) with mass spectrometry (5975C Agilent
Technology Inc, USA) with capillary column RTX-5silMS $(30 \mathrm{~m} \times 0.25 \mathrm{~mm}$ ID $\times 0.25 \mu \mathrm{m}$,). The analysis was performed using the split-less mode, and the injection volume was $2 \mu \mathrm{L}$. High-purity nitrogen was used as the carrier gas. The column condition was $40^{\circ} \mathrm{C}$, held for $2 \mathrm{~min}$, increased to $300{ }^{\circ} \mathrm{C}$ with a rate of $20^{\circ} \mathrm{C} / \mathrm{min}$, held for $15 \mathrm{~min}$. The $\mathrm{GC}-\mathrm{MS}$ interface was set at $280^{\circ} \mathrm{C}$. The MS detection was in selective ion monitoring (SIM) operating mode at an electron impact energy of $70 \mathrm{eV}$. Two or three mass fragments were selected for each compound. The most intense ion was used for quantification, and the other ions were used for confirmation of the presence of the compounds. The quantitative and qualitative ions and their relative ratios are listed in Table 2.

Because of the many sources that can contaminate a sample during analysis, phthalate analysis requires very high accuracy, proper preparation and purification of sorbent materials, cleanliness of laboratory equipment used in testing and avoidance of elements that may emit phthalates.
Table 2 Selected ion (at $\mathrm{m} / \mathrm{z}$ ) for individual PAEs

\begin{tabular}{llllrrr}
\hline Compounds & $\begin{array}{l}\text { Retention time } \\
(\mathrm{min})\end{array}$ & $\begin{array}{l}\text { Molar mass } \\
(\mathrm{g} / \mathrm{mol})\end{array}$ & $\begin{array}{l}\text { Typical } \\
\text { quantitation ions }\end{array}$ & Q1 & Q2 & Q3 \\
\hline DMP & 9.83 & 194.18 & 163 & 77 & & \\
DEP & 10.68 & 222.24 & 149 & 177 & & \\
DBP & 12.65 & 278.35 & 149 & 150 & 223 & 205 \\
BBP & 14.42 & 312.37 & 149 & 91 & 206 & 238 \\
DEHP & 15.17 & 390.56 & 149 & 167 & 279 & 104 \\
DNOP & 15.97 & 390.56 & 279 & 149 & 167 & 261 \\
\hline
\end{tabular}


Therefore, the first step was to test for phthalate purity of all the materials: glass fibre filters, polyurethane foam, XAD-2 media from factory-fabricated tubes and the reagents: dichloromethane (DCM) and acetone (AC) used. The phthalates determined in the tested samples were below the quantification of the method.

In the second stage, phthalate contamination of the XAD-2 bed, polyurethane foam and fibreglass filters was tested under laboratory conditions during air sampling through a set consisting of an IOM probe and an XAD-2 tube, the XAD-2 tube itself, the IOM probe with a foam and a filter and finally the empty IOM probe connected to the $\mathrm{XAD}-2$ tube. The air was sampled for $4 \mathrm{~h}$ at a rate of $2 \mathrm{~L} /$ min. Then, after desorption with AC/DCM (1:1) mixture in ultrasounds, GC/MS analysis for phthalates was performed. Phthalates (DEP, DBP and DEHP) were detected and determined only in the XAD-2 resin at the concentration levels below $0.2 \mu \mathrm{g} / \mathrm{m}^{3}$. The results of the experiment $(n=5)$ indicated that the contamination came from the IOM probe holder.

Next, phthalate recoveries during desorption were also tested, taking into account the air sampling stage. Recovery from filters for 6 phthalates was in the range of $80-100 \%$, for XAD-2 66-88\% and for PUF 86-112\%. The recovery values were included in the calculation of the concentrations of phthalates within the study. For 6 phthalates, the linearity range of the calibration curve was determined from 0.016 to $1 \mu \mathrm{g} / \mathrm{mL}$. At $720 \mathrm{~L}$ of air intake, the quantification for the glass fibre filter and polyurethane foam (PUF) was 0.066 and for XAD-2, it was $0.022 \mu \mathrm{g} / \mathrm{m}^{3}$. The total precision value for 6 phthalates was $5.5 \%$, while the expanded uncertainty for phthalates did not exceed $25 \%$.

\section{Results and discussion}

The results of the presented study showed that 2-6 phthalates were determined in air samples taken in the majority of selected companies. This finding is important due to the fact that three of the determined phthalates DEHP, DBP, BBP are classified as toxic for reproduction under EU chemicals legislation (category 1). DNOP is on the EDCs list, but without classification. DMP is not classified as an endocrine active substance while DEP is in category 3, which means that there is no evidence or no data available on its endocrinedisrupting effects.

The results of the qualitative determination of phthalates in the company A have shown that 3 phthalates dimethylphthalate (DMP), diethylphthalate (DEP), dibutylphthalate (DBP) were determined in the gas phase and 6 of them in both respirable and inhalable fractions [dimethylphthalate (DMP), diethylphthalate (DEP), dibutylphthalate (DBP), benzylbutylphthalate (BBP), bis(2-ethylhexyl) phthalate

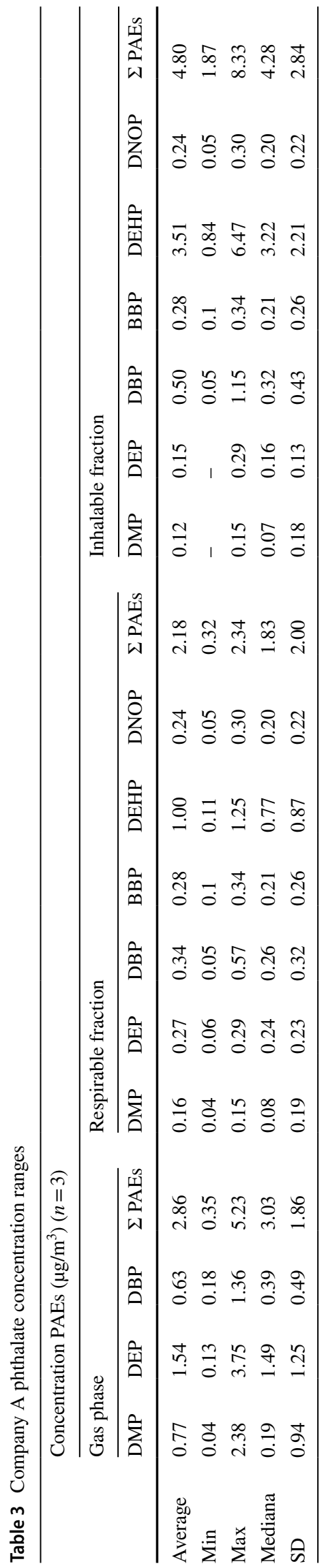




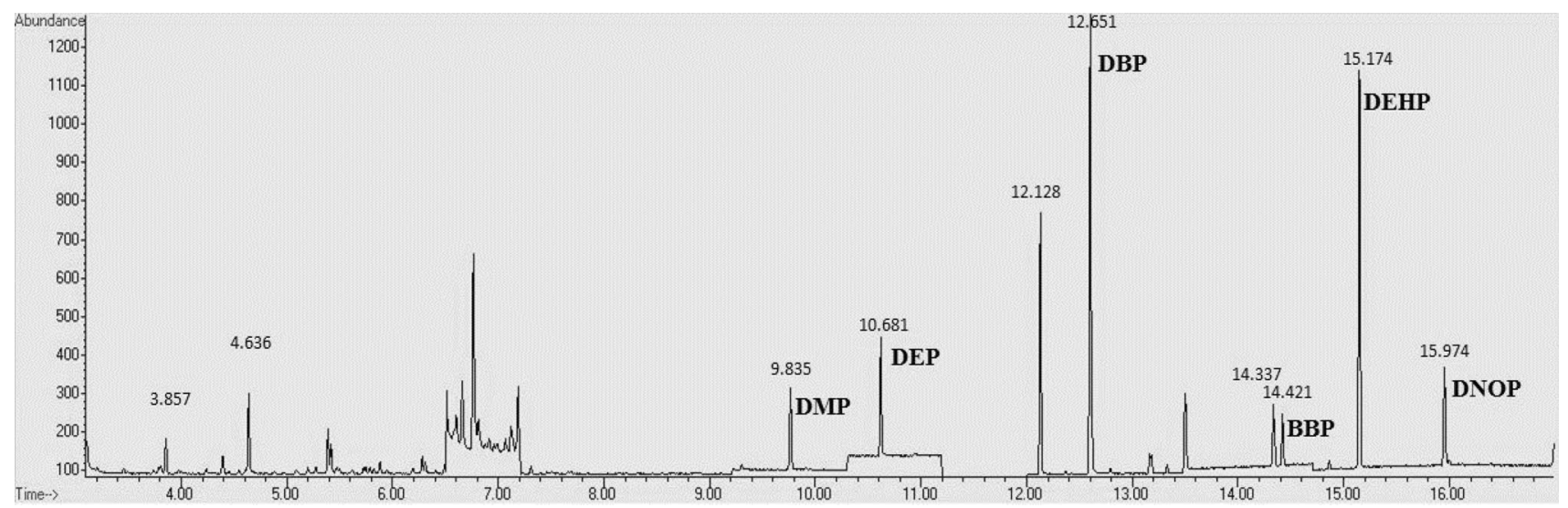

Fig. 1 Exemplary GC/MS/SIM chromatogram of phthalates determined in a respirable fraction at the company A at the bonding of plastic parts site

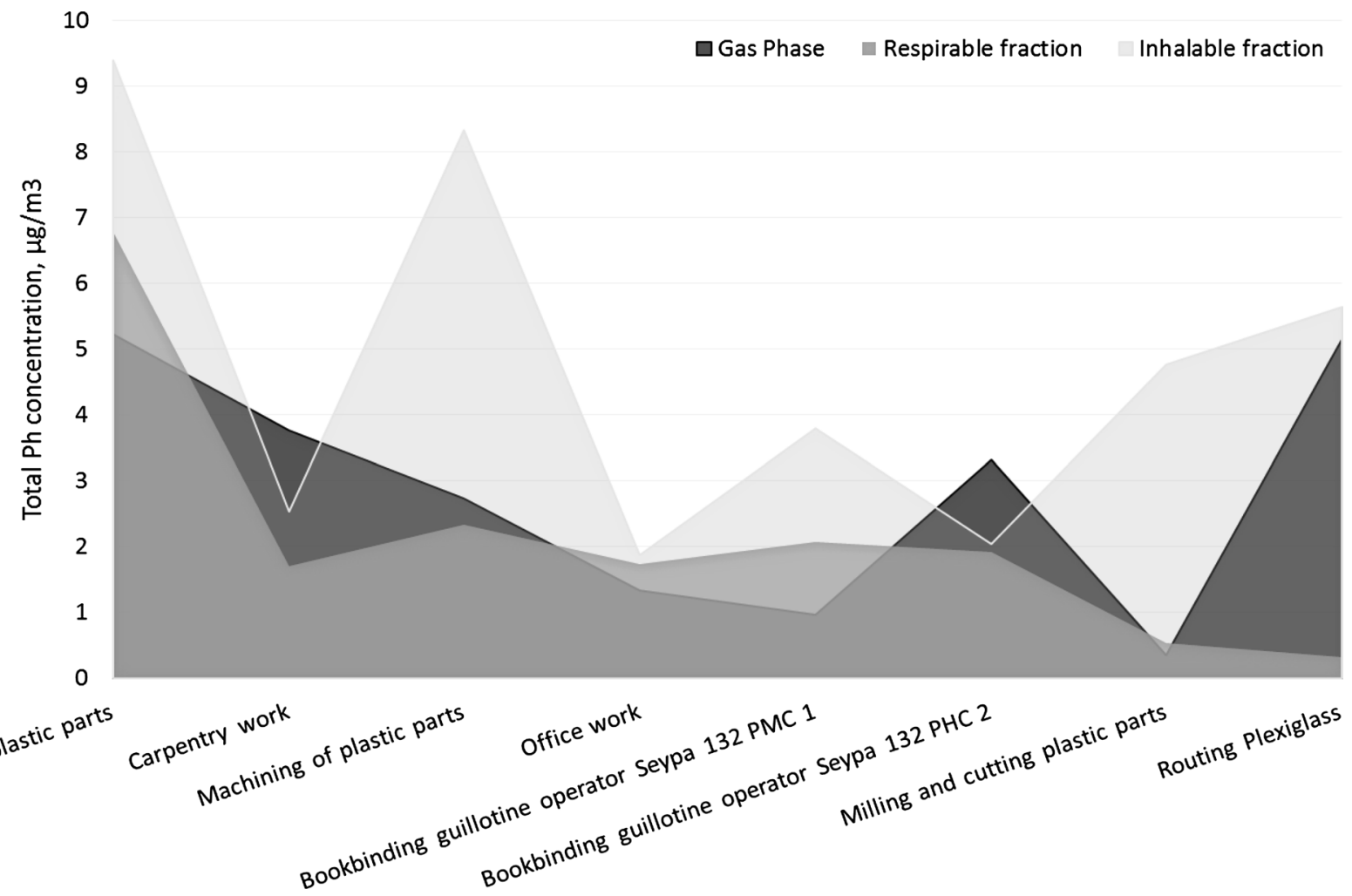

Fig. 2 Total concentrations of phthalates in the gaseous phase, respirable and inhalable fractions at the various measuring points of company A

(DEHP) and di- $n$-octylphthalate (DNOP)]. As it was previously explained by Pei et al. (2013) because of high boiling point and semi-volatile characteristics of phthalates, DMP and DEP often exist in indoor air in gaseous form, with small molecular weight and higher saturated vapour pressure, while, for example, DEHP with larger molecular weight mainly exists in the particle phase.

The concentration ranges of the individual phthalates and their total concentration in the gaseous phase, inhalable and respirable fractions marked in company A are presented in Table 3.

For phthalates classified as EDCs substances (category 1 ), the highest concentration in the gaseous phase was determined for DBP $\left(1.36 \mu \mathrm{g} / \mathrm{m}^{3}\right)$ and in the respirable and inhalable fraction for DEHP at $1.25 \mu \mathrm{g} / \mathrm{m}^{3}$ and $6.47 \mu \mathrm{g} / \mathrm{m}^{3}$, respectively. The highest total concentration of phthalates both in the gaseous phase and in the respirable and inhalable fractions was determined at the plastic elements binding station and amounted to: $5.32,6.79$ and $9.39 \mu \mathrm{g} / \mathrm{m}^{3}$, 
Table 4 Total concentration of phthalates in the company $\mathrm{S}$

\begin{tabular}{llll}
\hline Wokplace at the company $\mathrm{S}$ & \multicolumn{2}{l}{$\begin{array}{l}\text { Total concentration PAEs }(n=3) \\
(\Sigma \mathrm{PAEs}) \mu \mathrm{g} / \mathrm{m}^{3}\end{array}$} \\
\cline { 2 - 4 } & Gas phase & $\begin{array}{l}\text { Respirable } \\
\text { fraction }\end{array}$ & $\begin{array}{l}\text { Inhal- } \\
\text { able } \\
\text { fraction }\end{array}$ \\
\hline Small container extruder & 1.78 & 0.11 & 5.96 \\
Plastic dispenser & 1.48 & 0.21 & 1.78 \\
Large container extruder & 2.92 & 0.48 & 5.98 \\
\hline
\end{tabular}

respectively. Figure 1 shows exemplary chromatogram of phthalates determined in a respirable fraction at the company A at the site of plastic parts bonding. Figure 2 shows that the percentage of the sum of the phthalates defined in the respirable fraction relative to those defined in the inhalable fraction in company A varies depending on the process (workplace) and ranges from 5.7\% (at the Routing Plexiglass workstation) to $94 \%$ (Bookbinding guillotine 2).

The same 3 phthalates as in the company A (DMP, DEP and DBP) were determined in the gaseous phase in the company $S$ that produced plastic packaging. The concentration ranges of these compounds in the company were $0.15-0.37 \mu \mathrm{g} / \mathrm{m}^{3}$ (DMP), $0.87-1.5 \mu \mathrm{g} / \mathrm{m}^{3}$ (DEP) and $0.4-1.04 \mu \mathrm{g} / \mathrm{m}^{3}$ for DBP, which is classified to category 1 on the EDCs list. The maximum concentration of the sum of phthalates in the gaseous phase $\left(2.9 \mu \mathrm{g} / \mathrm{m}^{3}\right)$ was determined at the large container extruder (Table 4).

Figure 3 shows exemplary results of phthalates measurements in the inhalable and respirable fractions at 3 workstations in company $\mathrm{S}$. In the respirable fraction, the highest concentration was determined for DBP at $0.4 \mu \mathrm{g} / \mathrm{m}^{3}$. In the inhalable fraction, on the other hand, the highest concentrations were determined for DEHP at 2 workstations, i.e. at small and large container extruders. The DEHP concentration at both workstations was $3.7 \mu \mathrm{g} / \mathrm{m}^{3}$ (Fig. 2). At these two workplaces, the total concentration of phthalates in the inhalable fraction was also the highest and amounted to $5.9 \mu \mathrm{g} / \mathrm{m}^{3}$ (Table 4).

In the company producing rubber details for car accessories (company V), three phthalates (DMP, DEP, DBP) in the gaseous phase and two (DBP and DEHP) in the inhalable and respirable fractions were determined. During the vulcanization process in the rubber technologies, plastic rubber compounds by physical and chemical reactions change into highly elastic products. On this basis, workplaces where vulcanizing presses were located as a potential source of EDC emissions were selected. The concentration ranges of individual phthalates determined in the gaseous phase were as follows: $0.08-1.45 \mu \mathrm{g} / \mathrm{m}^{3}$ in case of DMP, $0.14-4.02 \mu \mathrm{g} /$ $\mathrm{m}^{3}$ for DEP and $0.27-3.89 \mu \mathrm{g} / \mathrm{m}^{3}$ for DBP. DBP was also found in the respirable fraction at the concentration range of $0.09-1.07 \mu \mathrm{g} / \mathrm{m}^{3}$. DEHP in the respirable fraction was at the level of $0.04-1.47 \mu \mathrm{g} / \mathrm{m}^{3}$ and in the inhalable fraction $0.51-8.77 \mu \mathrm{g} / \mathrm{m}^{3}$. DBE present in the inhalable fraction was in the range of 1.11-4.43 $\mu \mathrm{g} / \mathrm{m}^{3}$ (Table 5). The highest total phthalate concentration determined at the workstations with the vulcanizing press was $6.5 \mu \mathrm{g} / \mathrm{m}^{3}$ in the gaseous phase, $1.56 \mu \mathrm{g} / \mathrm{m}^{3}$ in the respirable fraction and $12 \mu \mathrm{g} / \mathrm{m}^{3}$ in the inhalable fraction (Fig. 4).

In the company $\mathrm{D}$, where PVC, PP and drainage pipes were produced, the concentrations of individual phthalates and their total concentrations in the gaseous phase, inhalable fraction and respirable fraction are shown in Table 6. As in the previous plants, in the gaseous phase the same 3 phthalates were determined. The concentrations of DMP and DEP were determined in the following ranges: $0.04-0.8 \mu \mathrm{g} / \mathrm{m}^{3}$ and $0.3-1.8 \mu \mathrm{g} / \mathrm{m}^{3}$, respectively. DBP concentration in the gas phase was in the range of $0.8-3.1 \mu \mathrm{g} / \mathrm{m}^{3}$. The maximum concentration of DBP was $0.35 \mu \mathrm{g} / \mathrm{m}^{3}$ for mixing composites workplace and $1.26 \mu \mathrm{g} / \mathrm{m}^{3}$ of DEHP for extrusion of thin pipes from polypropylene. In the inhalable fraction, DBP was determined at all workplaces at the production line and DEHP at 6 stations, except for injection moulding machine for PP and PVC. The concentration range of these phthalates in the inhalable fraction was $0.41-2.95 \mu \mathrm{g} / \mathrm{m}^{3}$ for DBP and $0.5-4.11 \mu \mathrm{g} / \mathrm{m}^{3}$ for DEHP (Fig. 5). In total, the highest concentration of phthalates in the respirable $\left(1.57 \mu \mathrm{g} / \mathrm{m}^{3}\right)$ and inhalable fraction $\left(7 \mu \mathrm{g} / \mathrm{m}^{3}\right)$ was determined during the extrusion of thin tubes (Fig. 6). The highest total concentration of phthalates in the gaseous phase was determined for extrusion of thick PVC $\left(5.5 \mu \mathrm{g} / \mathrm{m}^{3}\right)$.

Comparing the composition of the air in terms of the presence of phthalates, it can be concluded that different environments are the source of certain phthalates. This is also confirmed by the literature studies (Ying Chen et al. 2018; Song et al. 2015). Most phthalates in the air were identified in the company A, where ventilation was not used, but the total concentrations did not indicate that they were higher than in other plants. For example, in the inhalable fraction 6 phthalates in company A, while in company V, only 2 phthalates (DBP and DEHP) were identified. As a result, this leads to different air and dust compositions depending on the company. Phthalate emissions are also influenced by the type of process, its temperature and the materials used. In the case of company A, these were different types of plastics, and in company $\mathrm{V}$ rubber blends were processed.

\section{Conclusion}

The analysis of the results indicates that in all investigated companies, the following phthalates dominated in the air in the gas phase: dimethyl (DMP), diethyl (DEP), dibutyl (DBP). The concentration of DBP, classified into category 1, represented a significant percentage (up to $75 \%$ in company 


\section{(A) Respirabile fraction}

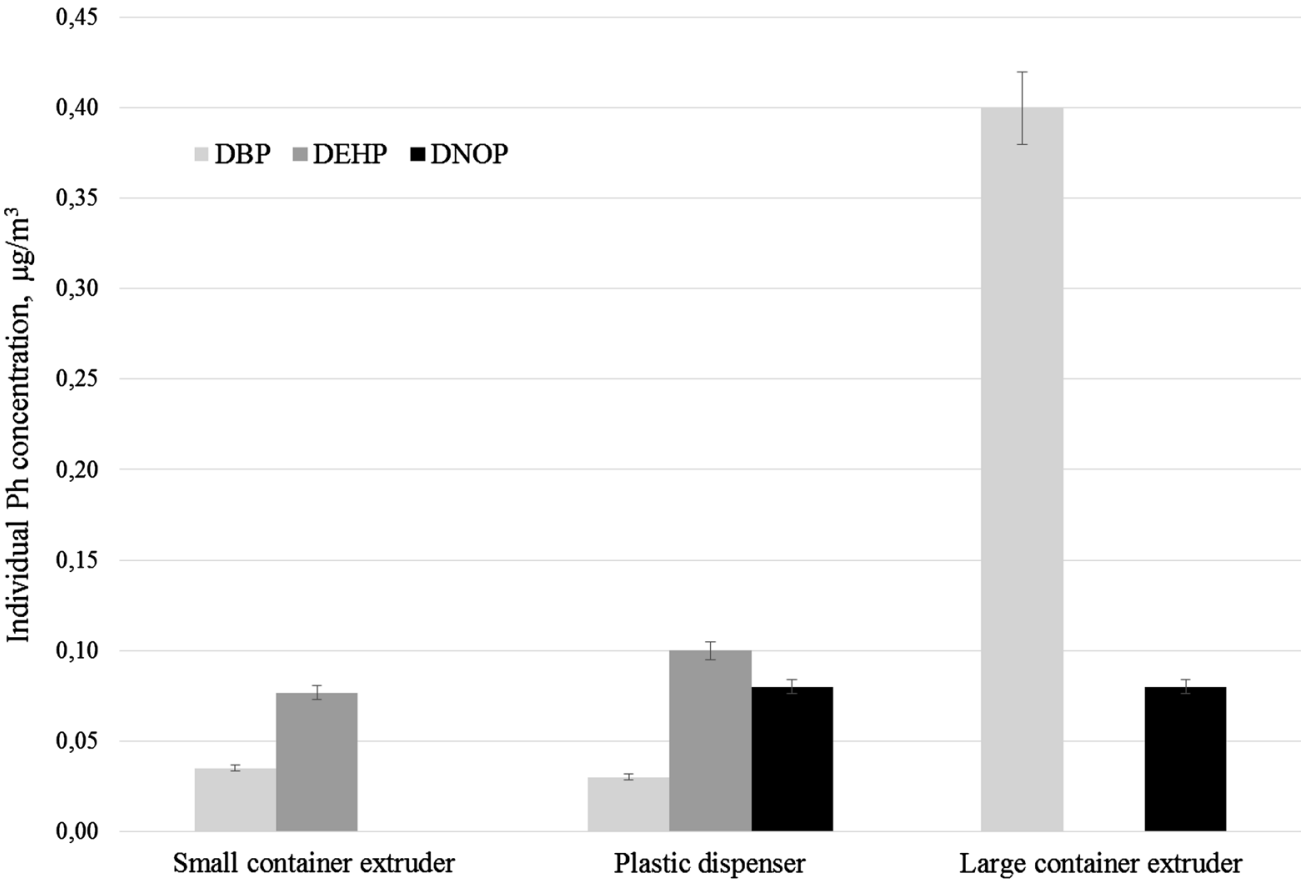

(B) Inhalable fraction

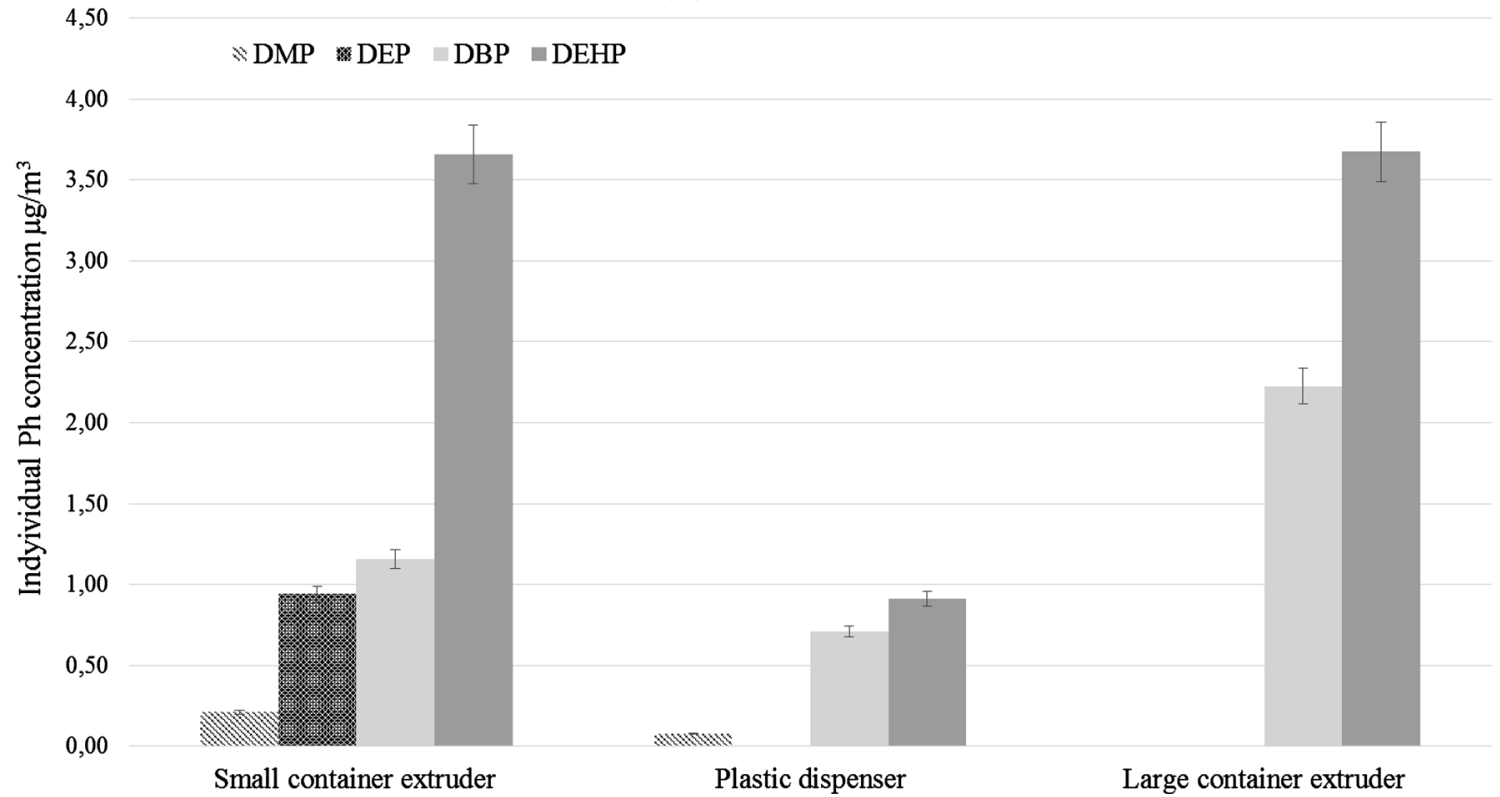

Fig. 3 Distribution of concentrations of individual phthalates in the respirable (a) and inhalable (b) fractions at individual workplaces in company $S$

D) of the total phthalates concentration in the gaseous phase. Moreover, phthalate esters can easily leach into the indoor environment and associate with dust particles. In the inhalable fraction, apart from DBP, also DEHP was detected and the total concentration of these 2 phthalates exceeded $81 \%$ (Companies V and D) of the sum of all phthalates determined in the inhalable fraction. Simultaneously, in the respirable fraction, phthalates represented on average up to a maximum of $50 \%$ of the phthalates determined in the inhalable fraction. Phthalates absorbed on respirable particles can be transported through the air and inhaled into the human respiratory system. This poses a health risk because the respirable fraction is deposited in the gas exchange area. The total phthalate concentrations in the respirable fraction 
Table 5 Concentration ranges of the individual phthalates and their sum in the gaseous phase, inhalable and respirable fractions, respectively, in the company $\mathrm{V}$

\begin{tabular}{|c|c|c|c|c|c|c|c|c|c|c|}
\hline & \multicolumn{10}{|c|}{ Concentration PAEs $\left(\mu \mathrm{g} / \mathrm{m}^{3}\right)(n=3)$} \\
\hline & \multicolumn{4}{|c|}{ Gas phase } & \multicolumn{3}{|c|}{ Respirable fraction } & \multicolumn{3}{|c|}{ Inhalable fraction } \\
\hline & DMP & DEP & DBP & $\Sigma$ PAEs & DBP & DEHP & $\Sigma$ PAEs & DBP & DEHP & $\Sigma$ PAEs \\
\hline Average & 0.35 & 1.34 & 1.66 & 3.35 & 0.58 & 0.72 & 0.08 & 2.36 & 2.87 & 5.24 \\
\hline Min & 0.08 & 0.14 & 0.27 & 0.49 & 0.09 & 0.04 & 0.04 & 1.11 & 0.51 & 2.01 \\
\hline $\operatorname{Max}$ & 1.45 & 4.02 & 2.32 & 6.5 & 1.07 & 1.47 & 1.56 & 4.43 & 8.77 & 12.11 \\
\hline Mediana & 0.16 & 1.23 & 1.595 & 3.53 & 0.58 & 0.675 & 0.91 & 2.13 & 2.23 & 3.99 \\
\hline SD & 0.41 & 1.10 & 0.96 & 1.77 & 0.69 & 0.62 & 0.59 & 0.99 & 2.29 & 2.84 \\
\hline
\end{tabular}

14 - Gas phase $\quad$ Respirabile fraction Inhalable fraction

12

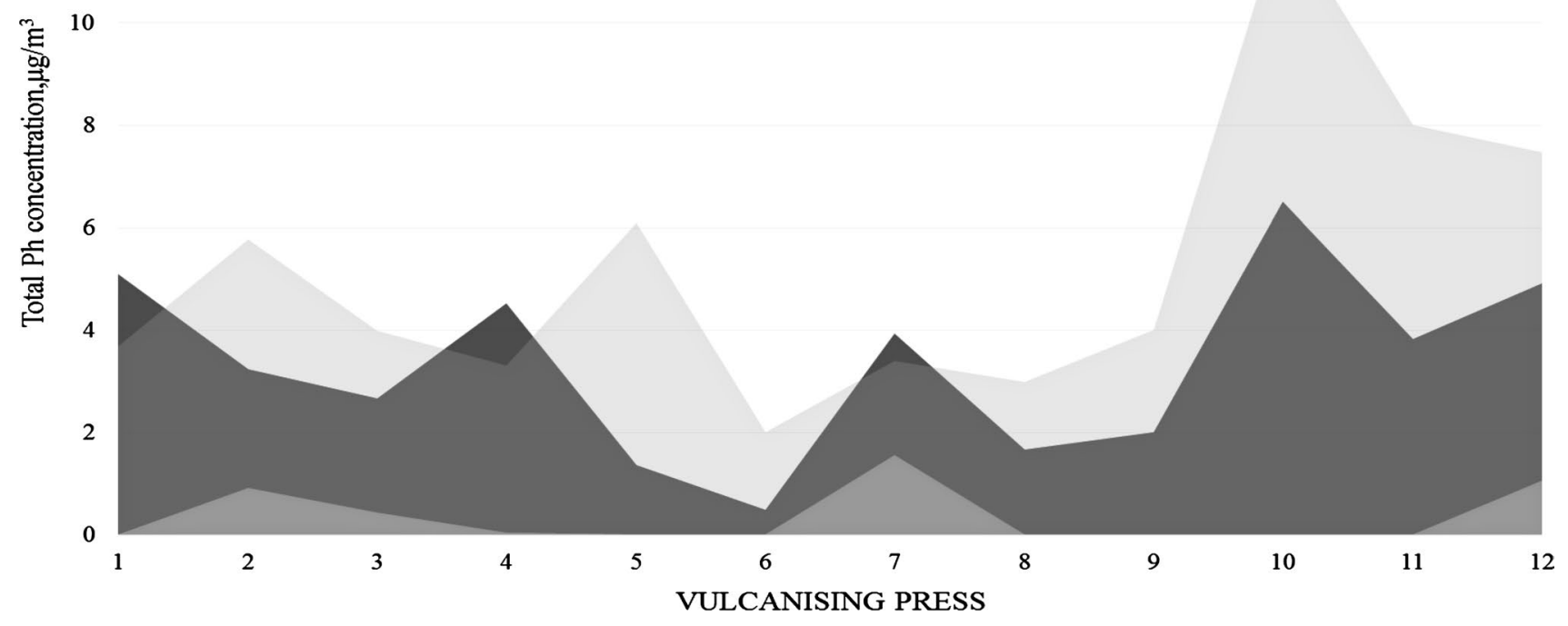

Fig. 4 Total concentrations of phthalates in the gaseous phase, respirable and inhalable fractions at individual measuring points in company V

Table 6 Concentration ranges of the individual phthalates and their sum in the gaseous phase, inhalable and respirable fractions, respectively, in the company D

\begin{tabular}{|c|c|c|c|c|c|c|c|c|c|c|}
\hline & \multicolumn{10}{|c|}{ Concentration PAEs $\left(\mu \mathrm{g} / \mathrm{m}^{3}\right)(n=3)$} \\
\hline & \multicolumn{4}{|c|}{ Gas phase } & \multicolumn{3}{|c|}{ Respirable fraction } & \multicolumn{3}{|c|}{ Inhalable fraction } \\
\hline & DMP & DEP & DBP & $\Sigma$ PAEs & DBP & DEHP & $\Sigma$ PAEs & $\overline{\mathrm{DBP}}$ & DEHP & $\Sigma$ PAEs \\
\hline Average & 0.22 & 0.91 & 1.96 & 3.08 & 0.12 & 0.26 & 0.38 & 1.46 & 1.47 & 2.94 \\
\hline Min & 0.04 & 0.31 & 0.77 & 1.12 & 0.00 & 0.00 & 0.00 & 0.41 & 0.00 & 1.06 \\
\hline Max & 0.88 & 1.79 & 3.06 & 5.45 & 0.31 & 1.26 & 1.57 & 2.95 & 4.11 & 7.05 \\
\hline Mediana & 0.12 & 0.51 & 2.20 & 2.82 & 0.08 & 0.00 & 0.08 & 1.42 & 0.95 & 2.31 \\
\hline SD & 0.29 & 0.64 & 0.86 & 1.61 & 0.15 & 0.48 & 0.63 & 0.78 & 1.36 & 2.07 \\
\hline
\end{tabular}

represented a different percentage of phthalates in the inhalable fraction. Depending on the company and the place of measurement, the phthalates determined in the respirable fraction relative to the inhalable fraction ranged from 5 to $93 \%$ in company A, from 2 to $11 \%$ in company $\mathrm{S}$, from 1 to $45 \%$ in company $\mathrm{V}$, from 8 to $51 \%$ in company D phthalates. 


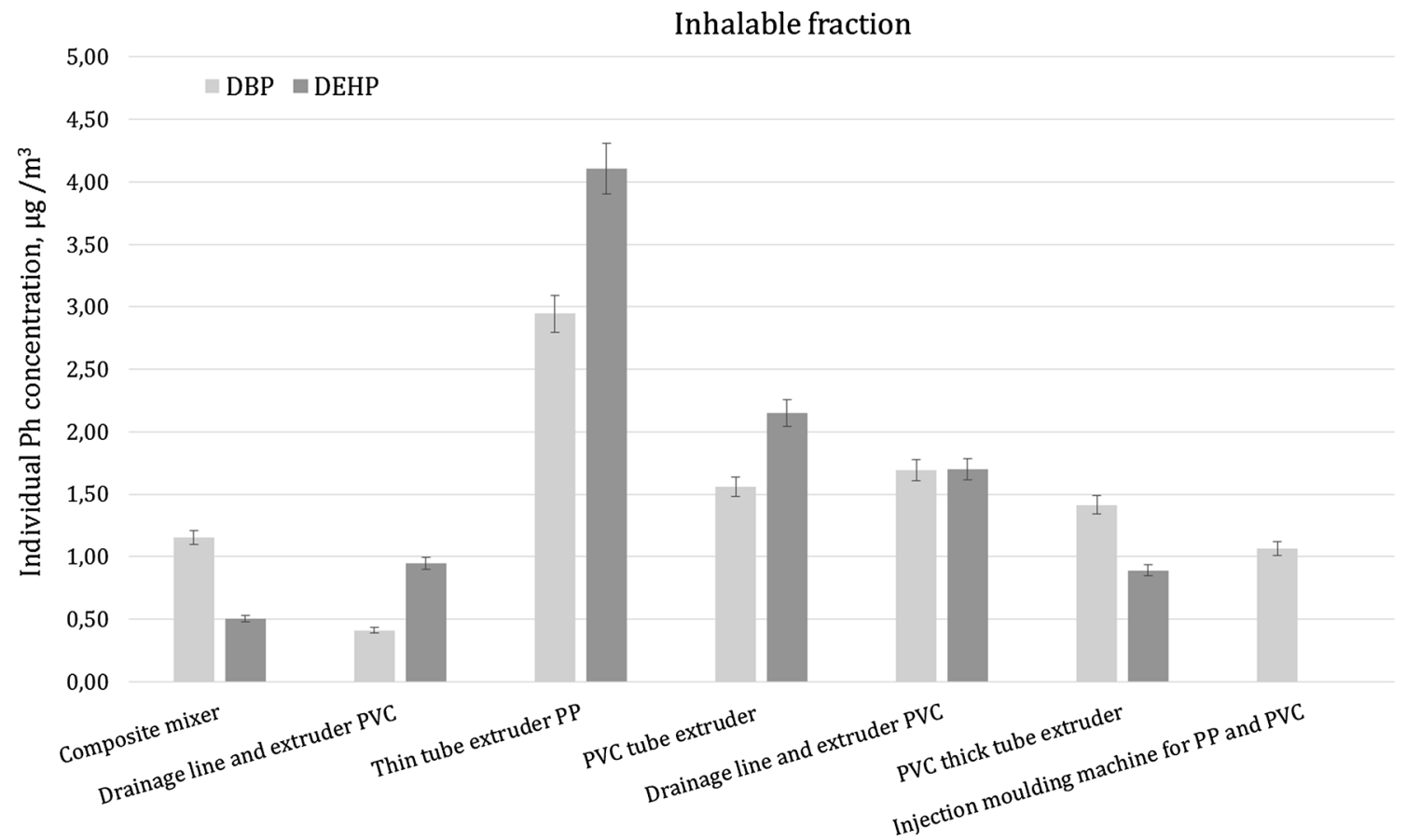

Fig. 5 Example of the concentration distribution of individual phthalates in the inhalable fraction at appropriate workstations in company D

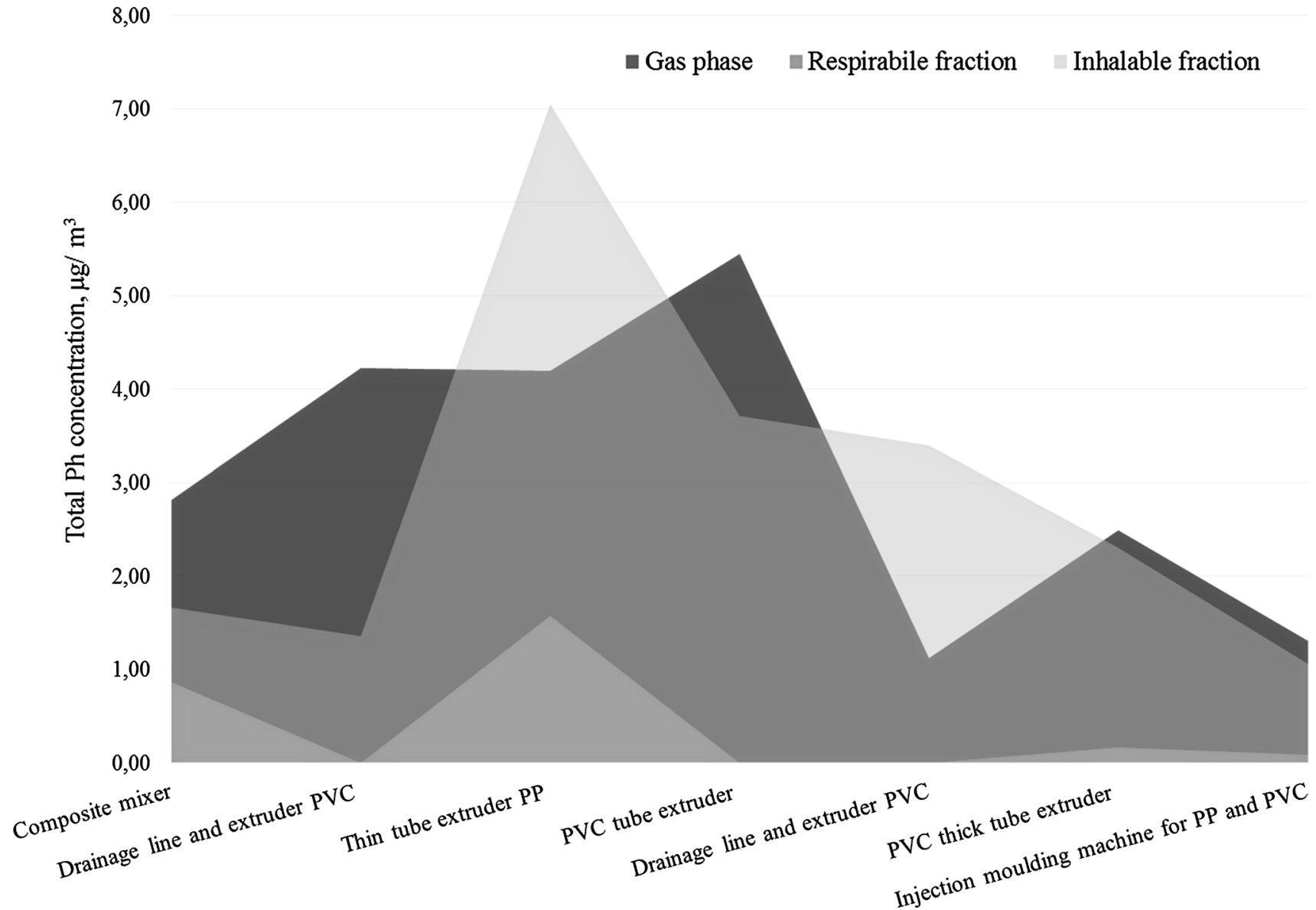

Fig. 6 Total concentrations of phthalates in the gaseous phase and the respirable and inhalable fractions at the individual workstations in company D 
Since phthalates disrupt the endocrine system, it is important to monitor the different environments into which they may be released. They provide different information on the occurrence and emission of phthalates into the air. The working environment in the exposure assessment can be an important source of risk of such compounds. According to Song et al. (2015), in order to accurately determine the state of a pollution, phthalates must be measured simultaneously in the gaseous phase and adsorbed on the particles. It should also be noted that for chemicals occurring in respiratory air in the form of suspended solids or liquid particles (droplets), the potential health risk depends on the particle size and mass concentration in the air, as particle size affects the place of their deposition in the respiratory tract and many occupational diseases tend to be associated with material deposited in individual functional areas of the respiratory system. Therefore, providing new data on levels of harmful substances and endocrine disruptors in various environments, including the workplace, is an essential and important step in risk assessment, workplace management and, as a result, a significant step towards setting threshold levels of occupational exposure.

Acknowledgements This paper is based on the results of a research task carried out within the scope of the fourth stage of the National Programme 'Improvement of safety and working conditions' supported in 2017-2019-within the scope of research and development-by the Ministry of Science and Higher Education/National Centre for Research and Development. The Central Institute for Labour Protection-National Research Institute (CIOP-PIB) was the Programme's main co-ordinator.

Open Access This article is distributed under the terms of the Creative Commons Attribution 4.0 International License (http://creativeco mmons.org/licenses/by/4.0/), which permits unrestricted use, distribution, and reproduction in any medium, provided you give appropriate credit to the original author(s) and the source, provide a link to the Creative Commons license, and indicate if changes were made.

\section{References}

Abdallah MAE, Harrad S, Ibarra C, Diamond M et al (2008) Hexabromocyclododecanes in indoor dust from Canada, the United Kingdom and the United States. Environ Sci Technol 42:6855-6861

Bergh C, Torgrip R, Ostman C (2010) Simultaneous selective detection of organophosphate and phthalate esters using gas chromatography with positive ion chemical ionization tandem mass spectrometry and its application to indoor air and dust. Rapid Commun Mass Spectrom 24:2859-2867

Bui T, Giovanoulis G, CousinsA P, Magnar J, Cousins IT, de Wit CA (2016) Human exposure, hazard and risk of alternative plasticizers to phthalate esters. Sci Total Environ 541:451-467

Chen Y, Lv D, Li X, Zhu T (2018) $\mathrm{PM}_{2.5}$-bound phthalates in indoor and outdoor air in Beijing: seasonal distributions and human exposure via inhalation. Environ Pollut 241:369-377

Chi C, Xia M, Zhou C, Wang X, Weng M, Shen X (2017) Determination of 15 phthalate esters in air by gas-phase and particle-phase simultaneous sampling. J Environ Sci 55:137-145. https://doi. org/10.1016/j.jes.2016.01.036

Colborn T, vom Saal FS, Soto AM (1993) Developmental effects of endocrine-disrupting chemicals in wildlife and humans. Environ Health Perspect 101:378-384

Cooper RL, Kavlock RJ (1997) Endocrine disruptors and reproductive development: a weight-of-evidence overview. J Endocrinol 152:159-166

Dodson RE, Nishioka M, Standley LJ, Perovich LJ, Brody JG, Rudel RA (2012) Endocrine disruptors and asthma-associated chemicals in consumer products. Environ Health Perspect 120(7):935-943

Han Z-X, Lin L, Fan Y, Zou C (2018) Environmental risk assessment of the emerging EDCs contaminants in Guan river of Jiangsu in Chin. Acad J Sci Res. https://doi.org/10.15413/ajsr.2018.0474

Hazard Prevention and Control in the Work Environment: Airborne Dust WHO/SDE/OEH/99.14. https://www.who.int/occupation al_health/publications/en/oehairbornedust3.pdf. Accessed 6 March 2019

Hines CJ, Yau AY, Zuniga MM, Wells JR, Nilsen Hopf NB, Camann DE (2010) Development of a personal dual-phase air sampling method for phthalate diesters. J Environ Monit 12(2):491-499

IARC Working Group on the Evaluation of Carcinogenic Risk to Humans (2012) Chemical agents and related occupations. International Agency for Research on Cancer, Lyon (FR). (IARC monographs on the evaluation of carcinogenic risks to humans, no. 100F.) Occupational exposures in the rubber-manufacturing industry. https://www.ncbi.nlm.nih.gov/books/NBK304412/. Accessed 6 March 2019

Johns LE, Cooper GS, Galizia A, Meeker JD (2015) Exposure assessment issues in epidemiology studies of phthalates. Environ Int 85:27-39

Jurewicz J, Hanke W (2011) Exposure to phthalates: reproductive outcome and children health. A review of epidemiological studies. Int J Occup Med Environ Health 24(2):115-141

Kashyap D, Agarwal T (2018) Concentration and factors affecting the distribution of phthalates in the air and dust: a global scenario. Sci Total Environ. https://doi.org/10.1016/j.scitotenv.2018.04.158

Kim HY (2016) Risk assessment of di(2-ethylhexyl) phthalate in the workplace. Environ Health Toxicol. https://doi.org/10.5620/eht. e2016026

Kolena B, Petrovicova I, Pilka T, Pucherova Z, Munk M, MatulaB VV, Petlus P, Jenisova Z, Rozova Z, Wimmerova S, Trnovec T (2014) Phthalate exposure and health-related outcomes in specific types of work environment. Int J Environ Res Public Health 11(6):56285639. https://doi.org/10.3390/ijerph110605628

Liang GG, Cooka WD, Sautereaub HJ, Tcharkhtch A (2008) Diallyl orthophthalate as a reactive plasticizer for polycarbonate. Part 1: uncured system. Eur Polym J 44:366-375

Meeker JD, Sathyanarayana S, Swan SH (2009) Phthalates and other additives in plastics: human exposure and associated health outcomes. Philos Trans R Soc Lond B Biol Sci 364:2097-2113

Moreau-Guigon E, Chevreuil M (2014) Human exposure to endocrine disruptors via ambient air: an unknown health risk. Arch Mal Prof Environ 75:74-81

Pei XQ, Song M, Guo M, Mo FF, Shen XY (2013) Concentration and risk assessment of phthalates present in indoor air from newly decorated apartments. Atmos Environ 68:17-23

Philips EM, Jaddoe VWV, Trasande L (2017) Effects of early exposure to phthalates and bisphenols on cardiometabolic outcomes in pregnancy and childhood. Reprod Toxicol 68:105-118

Quintana JB, Rodil R, Lopez-Mahia P, Muniategui-Lorenzo S, PradaRodriguez D (2007) Optimisation of a selective method for the determination of organophosphorous triesters in outdoor particulate samples by pressurised liquid extraction and large-volume injection gas chromatography-positive chemical ionisation-tandem mass spectrometry. Anal Bioanal Chem 388:1283-1293 
Rudel RA, Camann DE, Spengler JD, Korn LR, Brody JG (2003) Phthalates, alkylphenols, pesticides, polybrominated diphenyl ethers, and other endocrine-disrupting compounds in indoor air and dust. Environ Sci Technol 37(20):4543-4553

Safe SH (2000) Environmental and dietary estrogens and human health: Is there a problem? Environ Health Perspect 108:487-493

Sathyanarayana S (2008) Phthalates and children's health. Curr Probl Pediatr Adolesc Health Care 38(2):34-49. https://doi. org/10.1016/j.cppeds.2007.11.001

Song M, Chi Ch, Guo M, Wang X, Cheng L, Shen X (2015) Pollution levels and characteristics of phthalate esters in indoor air of offices. J Environ Sci 28:157-162

Ten Dam G, Pardo O, Traag W, van der Lee M, Peters R (2012) Simultaneous extraction and determination of HBCD isomers and TBBPA by ASE and LC-MSMS in fish. J Chromatogr B 898:101-110

Tsuyoshi M, Sousuke S, Tohru N (2003) Determination of endocrine disruptors in automobile exhaust particulate matter. J Health Sci 49:72-75

Wallace LA, Pellizzari ED, Hartwell TD, Sparacino CM, Sheldon LS, Zelon H (1985) Personal exposures, indoor-outdoor relationships, and breath levels of toxic pollutants measured for 355 persons in New Jersey. Atmos Environ 19:1651-1661

Zota AR, Calafat AM, Woodruff TJ (2014) Temporal trends in phthalate exposures: findings from the national health and nutrition examination survey, 2001-2010. Environ Health Perspect 122(3):235-241 